\title{
The etiology and prevention of feeding intolerance paralytic ileus - revisiting an old concept Gerald Moss
}

Address: Rensselaer Polytechnic Institute, Biomedical Engineering Department, Troy, New York, USA

Email: Gerald Moss - gerald_moss@mossmed.com

Published: 17 April 2009

Annals of Surgical Innovation and Research 2009, 3:3 doi:10.1 186/1750-1 I64-3-3

This article is available from: http://www.asir-journal.com/content/3/I/3

tral Ltd.

This is an Open Access article distributed under the terms of the Creative Commons Attribution License (http://creativecommons.org/licenses/by/2.0), which permits unrestricted use, distribution, and reproduction in any medium, provided the original work is properly cited.

Received: 13 November 2008

Accepted: 17 April 2009

\begin{abstract}
Gastro-intestinal (G-I) motility is impaired ("paralytic ileus") after abdominal surgery. Premature feeding attempts delay recovery by inducing "feeding intolerance," especially abdominal distention that compromises respiration. Controlled studies (e.g., from Sloan-Kettering Memorial Hospital) have lead to recommendations that patients not be fed soon after major abdominal surgery to avoid this complication.

We postulate that when total fluid inflow of feedings, digestive secretions, and swallowed air outstrip peristaltic outflow from the feeding site, fluid accumulates. This localized stagnation triggers G-I vagal reflexes that further slow the already sluggish gut, leading to generalized abdominal distention. Similarly, vagal cardiovascular reflexes in susceptible subjects could account for the $1: 1,000$ incidence of unexplained bowel necrosis reported with enteral feeding.
\end{abstract}

We re-evaluated our data, which supports this postulated mechanism for the induction of "feeding intolerance." We had focused our efforts on postoperative enteral nutrition, with the largest reported series of immediate feeding of at least $100 \mathrm{kcal} / \mathrm{hour}$ after major surgery. We found that this complication can be avoided consistently by monitoring inflow versus peristaltic outflow, immediately removing any potential excess from the feeding site.

We fed intraduodenally immediately following "open" surgery for 31 colectomy and 160 consecutive cholecystectomy patients. The duodenum was aspirated simultaneously just proximal to the feeding site, efficiently removing all swallowed air and excess feedings. To salvage digestive secretions, the degassed aspirate was re-introduced manually (and later automatically) via a separate feeding channel.

Hourly assays were performed for nitrogen balance, serum amino acids, and for the presence of removed feedings in the aspirate. The colectomy patients had X-ray motility studies initiated $5-17$ hours after surgery.

Clinically normal motility and absorption resumed within two hours. Fed $\mathrm{BaSO}_{4}$ traversed secure anastomoses, to exit in bowel movements within 24-48 hours of colectomy. All patients were in positive protein balance within $2-24$ hours, with elevated serum amino acids levels and without adverse G-I effects.

Limiting inflow to match peristaltic outflow from the feeding site consistently prevented "feeding intolerance." These patients received immediate full enteral nutrition, with the most rapid resolution of postoperative paralytic ileus, to date. 


\section{Introduction}

We have the largest reported series of postoperative patients immediately fed $\geq 100 \mathrm{kcal} / \mathrm{hr}$ without encountering "feeding intolerance" We re-examined our data, reaching a conclusion that had escaped us at the time. Our patients had been spared the risk of overfeeding because we had avoided the trigger, which was localized distention at the enteral feeding site.

Our attention had been focused primarily on efficiently intercepting and removing swallowed air while feeding. We aspirated the proximal duodenum, where the fluid path was narrowed, efficiently removing that gas. Fortuitously, nutrition was introduced into the slightly more distal duodenum. Total inflow that exceeded the impaired peristaltic duodenal outflow refluxed freely within this short, relatively flaccid segment. This refluxing excess also was promptly removed via the more proximal duodenal aspiration orifices. The patients would not have fared as well had we fed into the jejunum.

We now postulate that when peristaltic outflow from the feeding site is exceeded by total inflow (feedings superimposed on digestive juices plus swallowed saliva and air), fluid accumulates at this proximal location. The vagally mediated reflex response is slowing of the already sluggish entire gut, leading to a "downhill spiral" of generalized abdominal distention, nausea, and malaise. Respiratory embarrassment develops secondarily. Unexplained bowel necrosis occurs after jejunal feeding, with a reported incidence of $1: 1,000$. This, too, might similarly follow vagal vascular reflexes in susceptible subjects [1].

Miedema, et al., at the University of Missouri, prospectively monitored jejunal pressure via the feeding catheter. Postoperative patients that developed "feeding intolerance" did demonstrate elevated feeding site pressure. However, the increased pressure developed too late to guide timely intervention [2]. Monitoring of volume, per se, apparently could be more useful.

Why do we want a safer means to feed early and aggressively? Postoperative metabolism resembles that of a growing child. Net protein synthesis is permissible and achievable, but only if adequate nutrition is made available. Trauma produces a hypermetabolic state. Increased energy output usually becomes the determinant of protein anabolism, and protein catabolism has been the rule. However, even net protein synthesis is possible. The major factor limiting adequate enteral nutrition at these times is paralytic ileus, an avoidable G-I complication [3].

No conventionally fed patient fully meets his increased nutritional needs for a variable period after major abdominal operation or comparable trauma. The potentially pro- tective responses (e.g., heightened immune competence and accelerated wound healing) are blunted, limited by the patient's reduced gut function. Everyone's goal is to shorten this vulnerable, uncomfortable, and hospital dependent period.

Applying the latest "fast-track" techniques has progressively reduced the duration and severity of postoperative G-I dysfunction. Patients begin eating, reach nutritional goals, and are now discharged sooner, but they still endure days of documented negative protein balances after major abdominal resective surgery. We describe a regimen for achieving the earliest resolution of paralytic ileus and positive protein balances, to date.

\section{Materials and methods}

The subjects were the author's 31 colectomy and 160 consecutive cholecystectomy patients (1962 - 1988), prior to the introduction of laparoscopy into general surgery. All cholecystectomy and nine of the earliest colectomy patients had a Moss ${ }^{\circledast}$ naso-duodenal feeding-decompression device inserted ( ${ }^{*}$ Moss Tubes, Inc., West Sand Lake, $\mathrm{NY}$ ). Subsequent bowel resection patients had the gastrostomy version of this feeding-decompression device placed. An elemental diet (Vivonex, Norwich-Eaton Pharmaceuticals, Norwich, NY) (now Nestle HealthCare Nutrition, Minnetonka, MN) was initiated at $100-300$ $\mathrm{kcal} /$ hour within minutes of surgery.

The duodenal aspirate was tested hourly (Clinatest ${ }^{\circledR}$ Tablets, Ames Co., Billerica, MA) for "reducing sugars," as a marker for the removed feeding solution. The "degassed" aspirate was filtered and returned manually via the feeding channel. Hourly nitrogen balances and serum amino acids were determined.

The nasal tube was removed the morning following surgery. The cholecystectomy patients were discharged after a bowel movement and tolerating a general diet. The colectomy patients transitioned to oral elemental diet and had $\mathrm{BaSO}_{4}$ X-ray motility study over the next 24 hours. They resumed a general diet and met the same discharge criteria.

The later colectomy patients, with placement of a gastrostomy version of the feeding-decompression device, had $\mathrm{BaSO}_{4}$ introduced with their feedings 4-6 hours following bowel resection and re-anastomosis. Motility was studied by X-ray for the duration of tube feeding.

\section{Results}

The aspirate became Clinatest ${ }^{\circledast}$ negative (reducing sugars absent) during the first or second postoperative hour. The total feedings were propelled forward thereafter by peristalsis. A maximum of $200 \mathrm{ml} /$ day of refed gastroduode- 
nal aspirate continued to reflux and was discarded. No patient developed abdominal distention or other signs of paralytic ileus or "feeding intolerance."

All patients had achieved positive nitrogen balance within 2-26 hours postoperative (Table 1). Similarly, serum branched chain amino acids rose above basal levels by $2-$ 12 hours following surgery.

X-ray motility studies showed clinically normal peristalsis, with contrast traversing secure, patent, and functional anastomosis, to outline the rectum within 24 hours. Permission was obtained to publish the studies. (Figures 1, 2, $3,4,5$ and 6).

The median time to discharge decreased to 48 hours, with the final four colectomy patients home uneventfully 24 hours after bowel resection and re-anastomosis. The 160:160 consecutive "open" cholecystectomy patients were discharged within 24 hours of surgery.

\section{Discussion}

Wangensteen studied the factors affecting gastrointestinal function and dysfunction. He reported 70 years ago that even the disruptive consequences of complete small bowel obstruction could be aborted if swallowed air was completely excluded [4]. He over-sewed the dog's termi- nal ileum, and simultaneously vented its cervical esophagus. His experimental subjects were adequately hydrated by "clysis," but were not otherwise nourished. They survived without intestinal distention for up to two months, ultimately dying of starvation.

We developed a labor intensive feeding-decompression regimen that mimicked Wangensteen's animal model, which we utilized experimentally and clinically for immediately postoperative gastric feeding [5] (Figure 7). In 1963 we reported on our first 24 patients at the Surgical Forum of the annual American College of Surgeons meeting [6].

The duration of clinically significant paralytic ileus was abbreviated to within two hours postoperatively. Positive protein balances similarly were achieved within hours of surgery. Nutrient absorption and X-ray motility studies documented the more rapid return of normal G-I function. To this day, that regimen allowed the earliest achievement of positive protein balances following colectomy or other trauma.

The patient's esophagus was aspirated to remove all swallowed air. Undiluted tracheo-bronchial secretions also were intercepted, demanding continuous irrigation for patency of the suction channel. Unlike Wangensteen's

Table I: Postoperative Protein Balances

\begin{tabular}{|c|c|c|c|c|c|c|}
\hline \multirow[b]{2}{*}{ Operation } & \multirow[b]{2}{*}{ Age } & \multirow{2}{*}{$\begin{array}{l}\text { Days } \\
\text { Fed }\end{array}$} & \multicolumn{2}{|c|}{ Average Daily Protein } & \multirow[b]{2}{*}{ Balance } & \multirow{2}{*}{$\begin{array}{l}\text { Hours to } \\
\text { (+) Balance }\end{array}$} \\
\hline & & & Catabolized & Fed & & \\
\hline I. Abdomino-perineal Resection & 79 & 2 & 88 & 163 & +75 & 15 \\
\hline 2. Abdomino-perineal Resection & 83 & 4 & 93 & 149 & +56 & 4 \\
\hline 3. Abdomino-perineal Resection & 29 & 2 & 35 & 41 & +6 & 24 \\
\hline 4. Abdomino-perineal Resection & 17 & 2 & 101 & 118 & +17 & 8 \\
\hline 5. Sigmoid Resection & 60 & 2 & 104 & 122 & +18 & 26 \\
\hline 6. Sigmoid Resection & 69 & 2 & 78 & 100 & +22 & 7 \\
\hline 7. Sigmoid Resection & 76 & 2 & 42 & 77 & +35 & 6 \\
\hline 8. Sigmoid Resection & 55 & 2 & 43 & 133 & +90 & 22 \\
\hline 9. Sigmoid \& Bladder Resection & 45 & 2 & 85 & 86 & +1 & 18 \\
\hline 10. Vagotomy & 41 & 1 & 88 & 100 & +17 & 7 \\
\hline II. Vagotomy & 64 & 2 & 104 & 154 & +50 & 6 \\
\hline 12. Vagotomy \& Pyloroplasty & 70 & 4 & 68 & 150 & +82 & 24 \\
\hline 13. Vagotomy \& Pyloroplasty & 45 & 2 & 84 & 100 & +16 & 18 \\
\hline 14. Vagotomy \& Pyloroplasty & 60 & 2 & 85 & 136 & +51 & 6 \\
\hline 15. Vagotomy \& Pyloroplasty & 57 & 2 & 106 & 189 & +83 & 6 \\
\hline 16. V \& P + Gastrectomy & 38 & 2 & 31 & 85 & +54 & 20 \\
\hline 17. V \& P + Gastrectomy + G.B. & 60 & 2 & 98 & 104 & +6 & 10 \\
\hline 18. Hysterectomy & 45 & 2 & 51 & 74 & +23 & 6 \\
\hline 19. Cholecystectomy & 49 & 2 & 65 & 72 & +7 & 24 \\
\hline 20. Cholecystectomy & 48 & 1 & 49 & 200 & $+|5|$ & 2 \\
\hline 21. Cholecystectomy & 38 & 2 & 82 & 86 & +4 & 17 \\
\hline 22. lleostomy Revision & 32 & I & 38 & 140 & +102 & 7 \\
\hline 23. Ovarian Cystectomy & 56 & 2 & 45 & 99 & +54 & 23 \\
\hline 24. Colostomy Closure & 62 & 1 & 54 & 190 & +136 & 4 \\
\hline
\end{tabular}

(Data presented at the 1963 Surgical Forum - American College of Surgery [6]) 


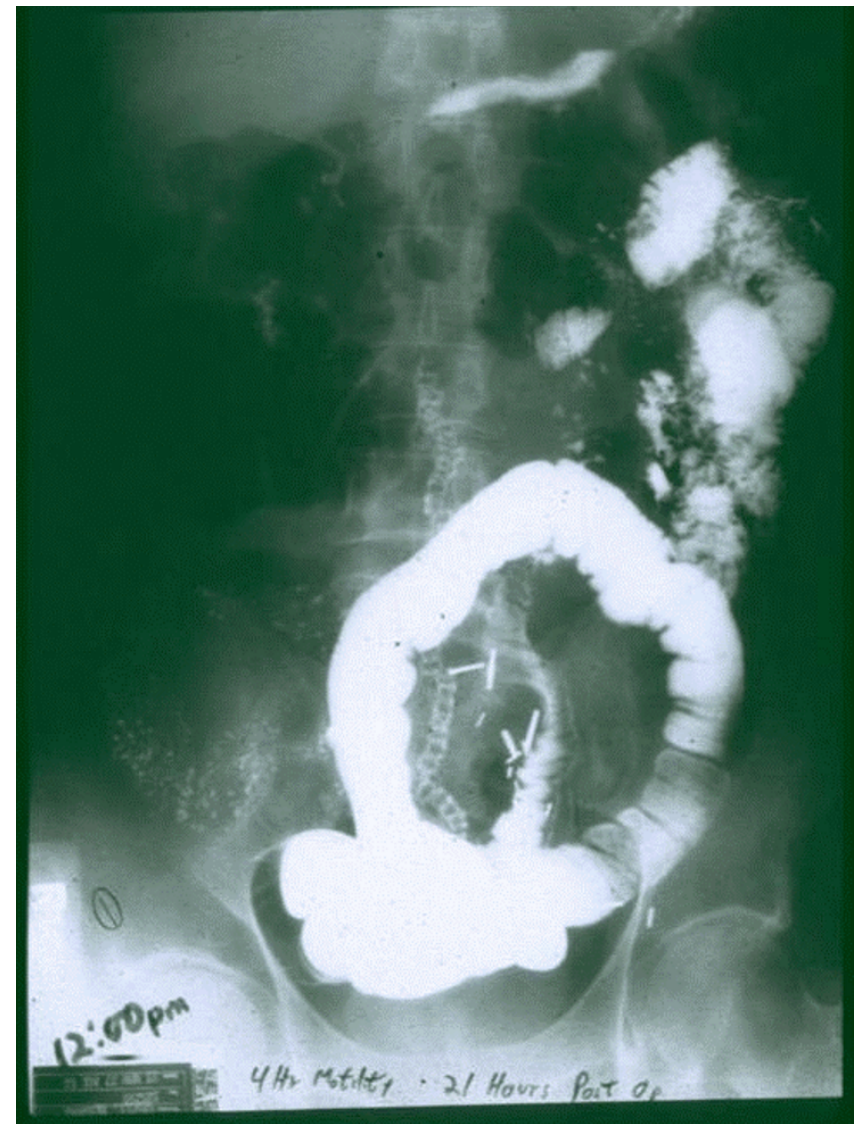

Figure I

66 y.o. male had sigmoid resection for carcinoma @ 3:00 pm. He was fed immediately for 17 hours via a double lumen, nasoduodenal catheter @ I00 kcal/hr. At 8:00 am the tube was removed, and $\mathrm{BaSO} 4$ swallowed. Serial $\mathrm{X}$-rays indicate normal motility. I2:00 noon -4 hour motility study, 2 I hours after surgery.

animal model, we provided a separate gastric channel for feeding and manually return of the filtered aspirate. Fear of gastric dilatation further increased the nursing workload, as we were obligated to frequently "check for residual."

The process was labor intensive, messy, and seldom performed outside of the research environment. The need for herculean nursing attention precluded wider acceptance of the original regimen. None-the-less, our clinical efforts were rewarded with preserved immediately postoperative G-I function.

Kehlet's Danish team reports on "fast-track" laparoscopic colectomy $[7,8]$. They conclude that application of advanced techniques ".... decreased the duration of ileus after colonic surgery to about 2 days, as compared with the usual 3 to 5 days." In Germany, Schwenk, et al., found

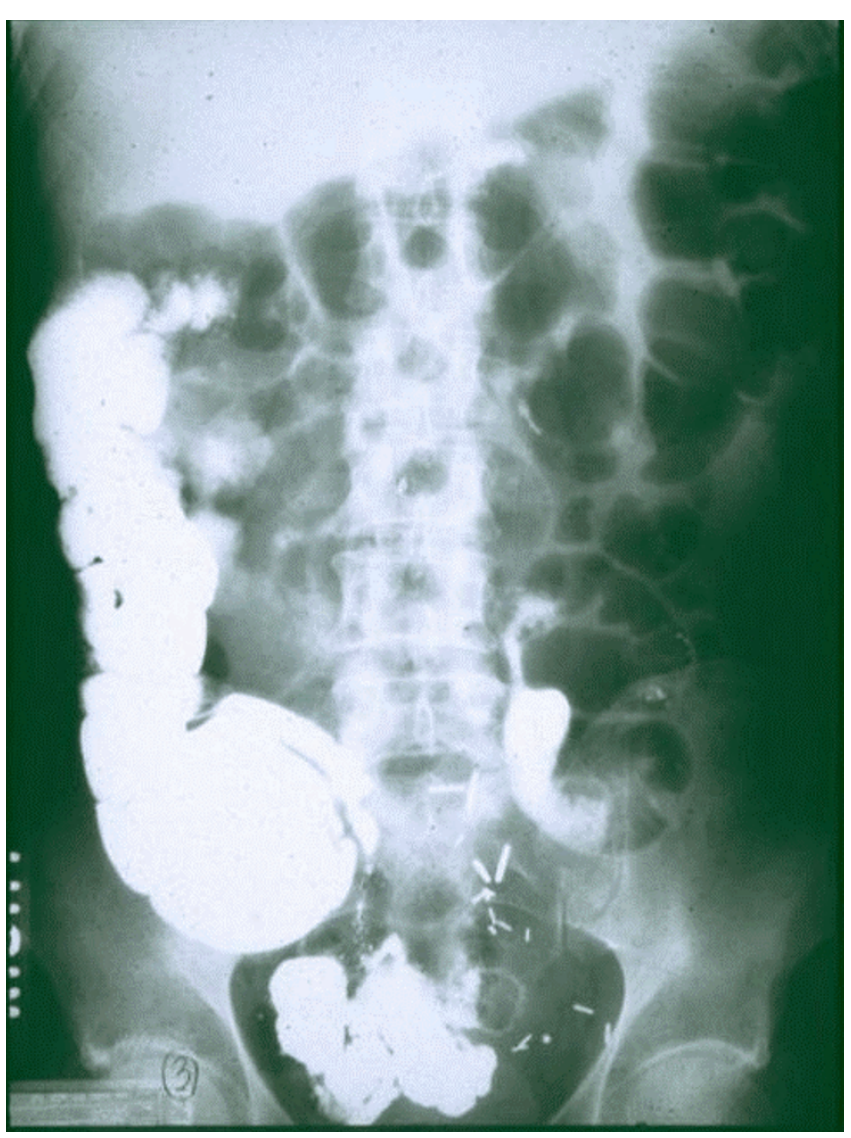

Figure 2

Normal motility. Contrast has reached the transverse colon. The more distal anastomosis is outlined by ring of stainless steel staples. 8:00 pm - 12 hour motility, 29 hours after sigmoid resection.

the time to both bowel movement and tolerance of oral feeding after laparoscopic colo-rectal resection is shortened significantly, but still approximates three days [9]. Hammarqvist, et al., report patients undergoing laparoscopic cholecystectomy develop days of negative protein balance and loss of muscle mass, despite receiving total parenteral nutrition [10].

The major shortcomings of our earliest catheters had been frequent clogging of the esophageal aspiration lumen. As modified since 1985, aspiration was extended distally into the proximal duodenum [11] (Figure 8). Air and liquid were intercepted and removed efficiently within the close confines at this location, confirmed radiographically. A separate duodenal channel fed elemental diet (plus the returned, "degassed" aspirate) just distal to the aspiration orifices.

We reported that decompression efficiency with this approach is more than twelvefold greater than gastric 


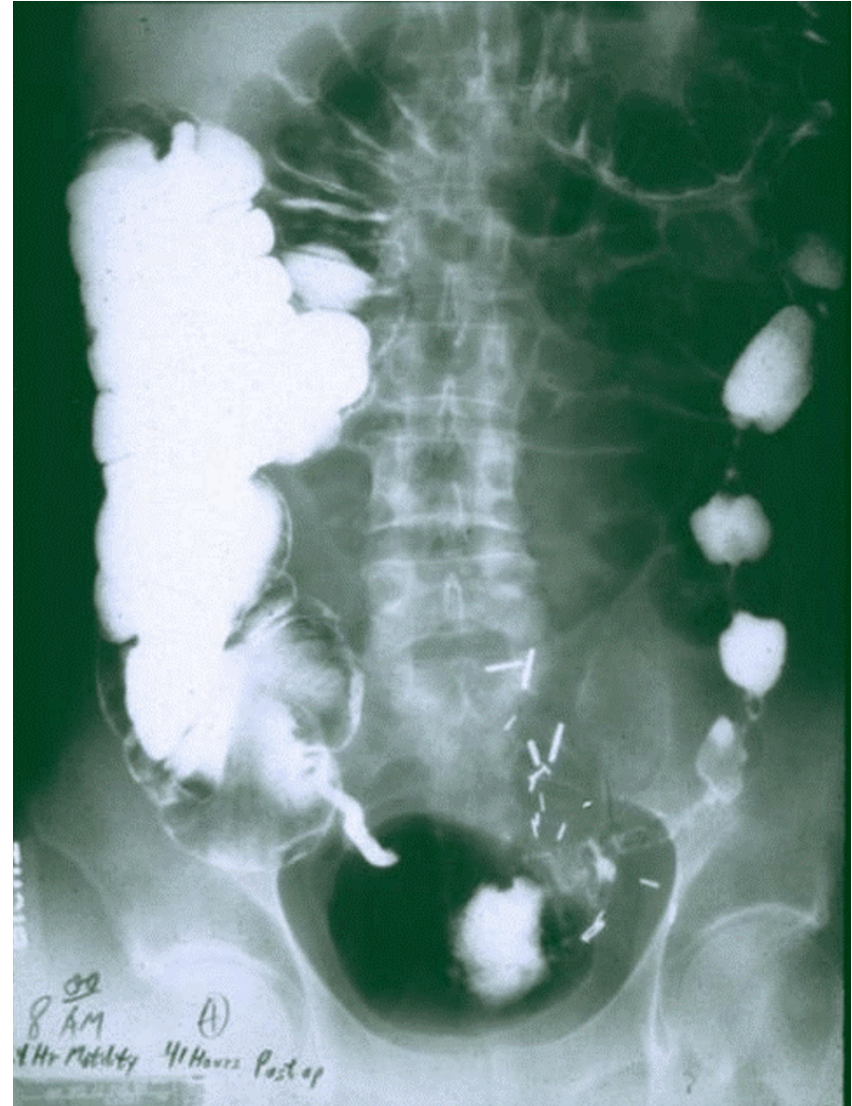

Figure 3

BaSO4 has traversed the secure and patent stapled anastomosis, to outline the rectum. The patient ate his Thanksgiving meal, and was discharged after a bowel movement within 48 hours of surgery. The $X$-ray shows a normal peristaltic pattern despite surgical trauma to the tissue. 8:00 am - 24 hour motility, 4I hours after sigmoid resection.

aspiration alone by conventional nasal or gastrostomy tube [12]. Suction applied to the stomach can be expected only to prevent gastric dilatation. The post-pyloric aspiration orifices remove air and digestive secretions that escape proximal removal, efficiently decompressing within this narrow segment of duodenum.

There is scant duodenal resistance to retrograde flow of excess feedings that outstrip peristaltic outflow. These reflux and also are removed by efficient suction within these close confines, apparently before vagal reflexes can be induced. No liquid or gas can traverse this narrow segment in either direction without being intercepted (Figure 4).

Increased volumes of aspirated digestive juices are removed to dilute the swallowed phlegm, and also to remove excess feeding. This "trade-off" to reduce the nurs-

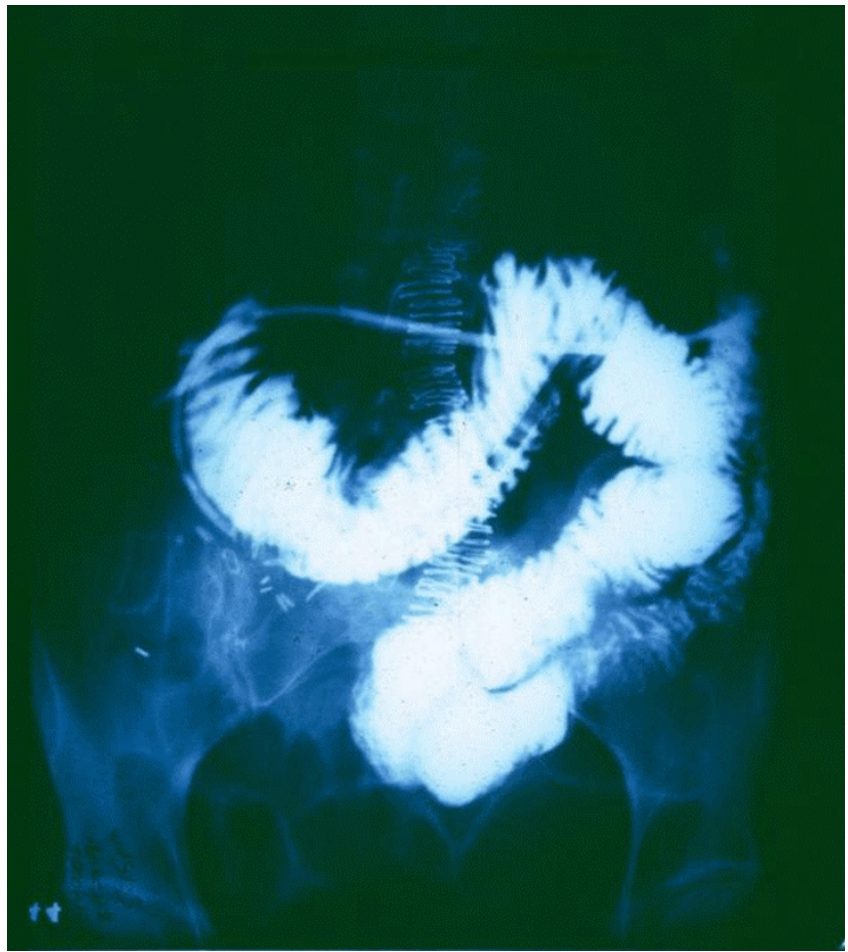

Figure 4

54 y.o. woman had a right hemicolectomy for carcinoma@ I I:00 am. Immediately fed with double lumen, feeding-decompression G-tube @ 300 kcal/hr. BaSO4 instilled via the feeding channel at rate exceeding peristaltic outflow. Note that no refluxing $\mathrm{BaSO} 4$ escaped aspiration, to enter the stomach. 4:00 pm - 5 minute motility, 5 hours after surgery.

ing workload substitutes the equivalent of a high output duodenal fistula, aspiration of 3,000 - 4,000 ml per day of gastric and pancreatic juices, saliva, bile, and succus. Without "refeeding," the patient requires additional intravenous infusions to replace this fluid, as well as laboratory studies to guide restoration of electrolyte balance.

Aspirate became devoid of elemental diet within two hours of surgery, using Clinatest ${ }^{\circledR}$ tablets as a check for the contained carbohydrate. In my personal experience with hundreds of surgical patients immediately fed @ 100$200 \mathrm{kcal} /$ hour, elemental diet spontaneously propelled by peristalsis beyond the ligament of Treitz continues prograde, where it is totally absorbed. We accidentally (and later deliberately) fed many patients at even higher rates. They suffered no ill effects when their capacity to absorb was exceeded. With air excluded, the unabsorbed elemental diet serves as a mild, self-limited cathartic (Figure 6) (Laxatives currently are an accepted component of "fasttrack" regimens.). None of our patients manifested "feeding intolerance," with increasing distention, nausea, etc. 


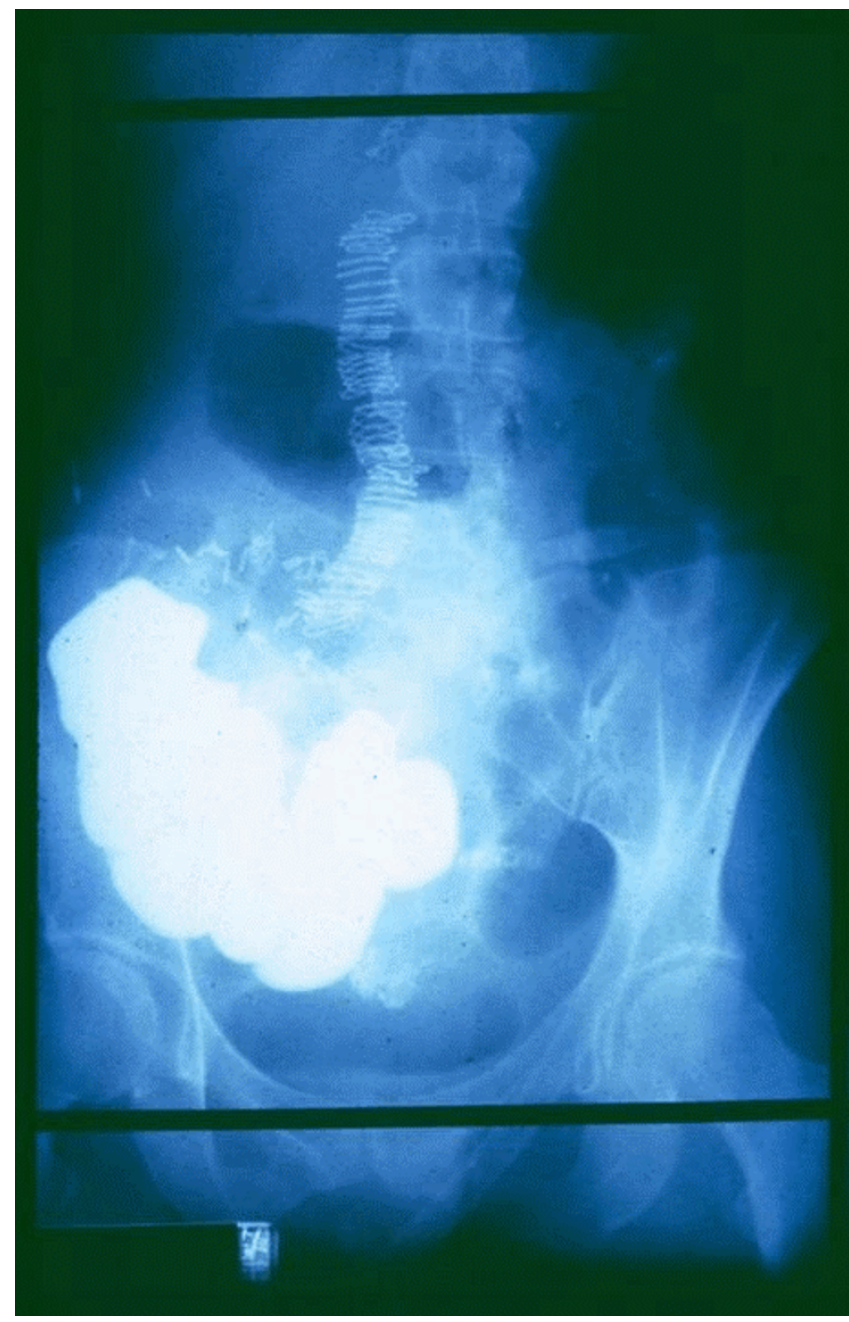

Figure 5

Clinically normal motility. Contrast is in the distal small intestine. 8:00 pm - 4 hour motility, 9 hours after a right hemicolectomy.

Absorption of a high carbohydrate load is analogous to superimposing a "glucose tolerance test" upon surgical stress, further increasing the patient's insulin requirement. Otherwise healthy young cholecystectomy patients $(<24$ years of age) respond by spontaneously raising their serum insulin levels as much as ten-fold above basal [13]. Diabetics and older (> 35 years of age) patients require insulin supplementation for optimum metabolic balance to avoid hyperglycemia during the initial 24 hours postoperatively. The patient reverts to his preoperative insulin requirement thereafter. Close plasma glucose control for seriously stressed patients is becoming a common practice, and is advised with postoperative "enteral hyperalimentation."

Clinically normal G-I motility and absorption resumed within hours for our 31 "open" colectomy patients, confirmed by the contrast X-ray studies. They consistently

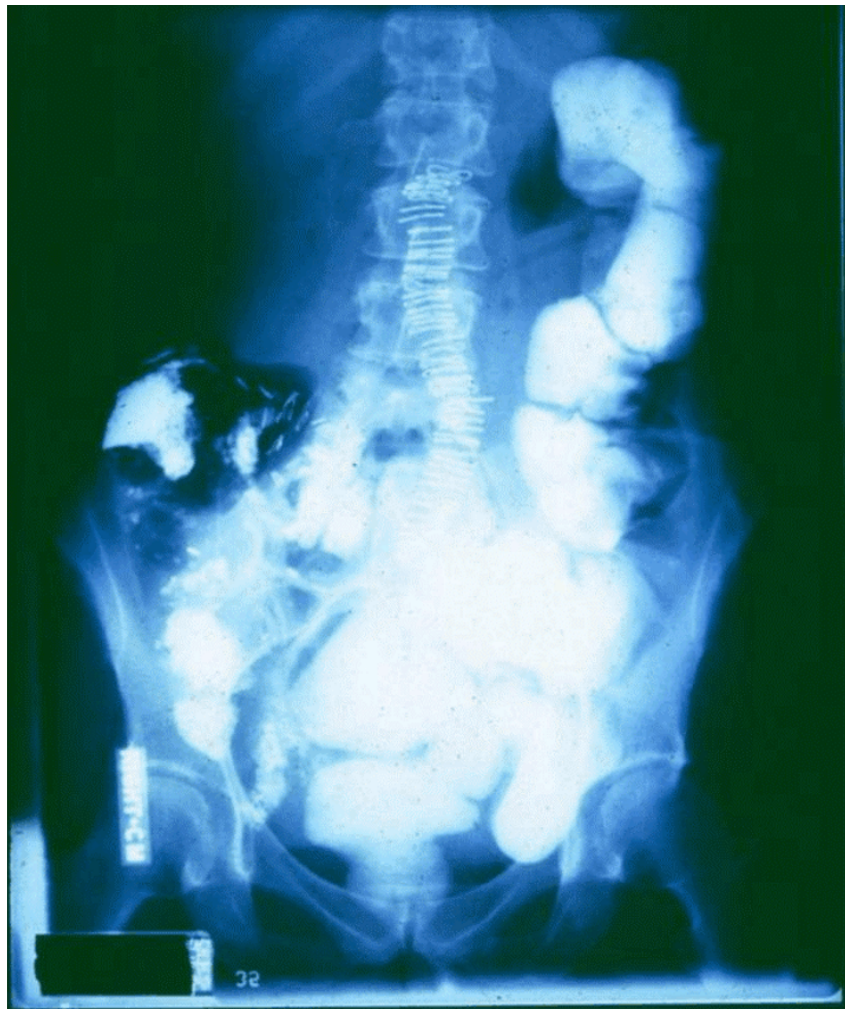

Figure 6

Normal motility. Dilute $\mathrm{BaSO} 4$ in the the colon and rectum. She tolerated a general diet, had a bowel movement, and was discharged within 24 hours of resective surgery. Note the laxative action of the excess feedings. 8:00 am - 16 hour motility, 2I hours after a right hemicolectomy.

entered positive protein balance after institution of full feeding [14]. Contrast traversed secure and functional anastomosis, to outline the rectum and exit spontaneously in a bowel movement. Their usual course was discharge after 24-48 hours of "open" bowel resection and re-anastomosis [15].

For our series of 160 consecutive "open" cholecystectomy patients before laparoscopy was introduced into general surgery, discharge uniformly was within 24 hours $[16,17]$. Empire (New York State) Blue Cross, jointly with the Visiting Nurse Association of Albany, prospectively studied 19 consecutive patients. They were interviewed preoperatively, the day of surgery, the day after discharge, and again 30 days later. All had continued adequate food intake and fully participated in "activities of normal living" [18].

Our digestive secretions contain large quantities of secretory globulins that are specific for our enteric organisms. Refeeding these secretions, and/or immediately heightened antibody synthesis, may provide sepsis protection. Our single infection (in an acute cholecystitis patient) fol- 


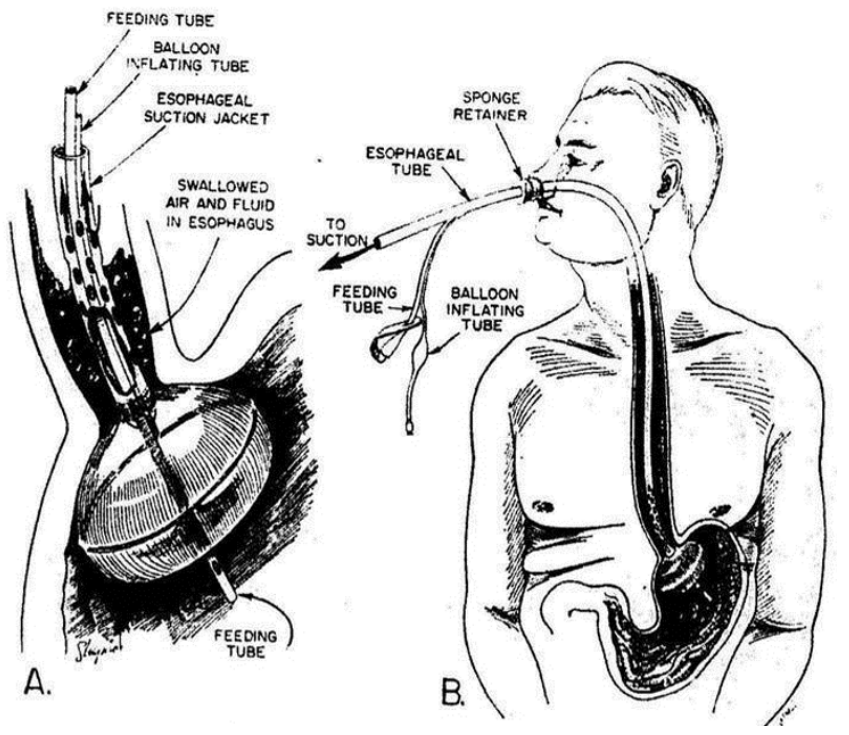

Figure 7

Progenitor Moss7 Nasal Tube (circa I96I) Reprinted with permission of the American College of Surgeons. Moss G. Nitrogen equilibrium in the early postoperative period. Surg Forum 1963; 14:67-69.

lowing 160 consecutive operations, is an apparent 90\% reduction in sepsis that supports this hypothesis.

Refeeding digestive secretions and immediate postoperative feeding may mimic prophylactic antibiotics, at lower financial and health costs. This requires further clinical study.

We consistently noted that elevation of serum amino acids within two hours accompanied positive protein bal-

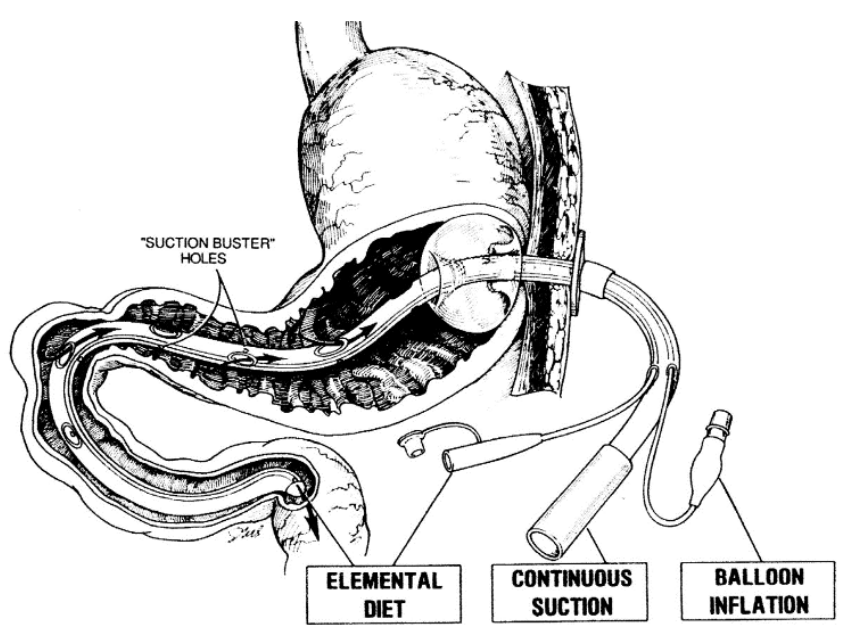

Figure 8

Current Moss Gastrostomy Tube (circa 1985). ance and net protein synthesis [19]. Serum branched chain amino acids rose immediately, rather than falling below basal for several days. This was confirmed by a surgical team in Cleveland in 34 consecutive "open" cholecystectomy patients fed with our regimen. Branched chain amino acids, essential for protein preservation and synthesis, rose above basal within one hour, and was sustained for the duration of feeding [20].

Experimental wounds reportedly benefit from this procedure to safely initiate early nutrition. We applied this regimen to dogs subjected to bowel resection. By 72 hours postoperatively for fed versus control beagles, wound DNA synthesis was increased six-fold.

By 96 hours, large bowel, intestinal, and abdominal wall wounds had bursting strengths doubled, tripled, and quadrupled, respectively. The stronger wounds showed accelerated collagen synthesis, i.e., procollagen content had doubled. Mature wound collagen of control dogs had diminished 50\%, while remaining unchanged for fed subjects [21]. A study of colectomy patients using our feedingdecompression regimen in New Zealand confirmed early increased wound procollagen in their experimental, simultaneous forearm wounds [22].

Immune protein synthesis shared in the accelerated protein synthesis associated with immediate "enteral hyperalimentation." Production of immune globulins doubled experimentally during the initial 24 hours [23]. Our animal findings were reproduced clinically in a controlled study of radical urological surgery at Roswell Park (Buffalo, NY) [24,25]. Their immediately fed patients achieved statistically significant higher levels for both plasma amino acids and immune protein (fibronectin) than unfed controls.

With this regimen, secretory globulins in digestive juices that target enteric organisms are neither removed nor sequestered, but carried to the patients' lower G-I tract soon after surgery. These may provide protection against nosocomial infection during the early postoperative period, when the patient is most vulnerable to infection by his own gut organisms.

The traumatized and vulnerable patient pays a hidden "price" for delayed or suboptimal enteral nutrition. Härtl, et al., reported a prospective study of 797 severe TBI (traumatic brain injury) patients treated at 22 New York State trauma centers from 2000-2006 [26].

"Patients who were not fed within 5 and 7 days after TBI had a 2- and 4-fold increased likelihood of death, respectively. The amount of nutrition in the first 5 days was related to death; every $10-\mathrm{kcal} / \mathrm{kg}$ decrease in 
caloric intake was associated with a $30-40 \%$ increase in mortality rates."

Jeschke, et al., showed that forced feeding lessened the hypermetabolic immune consequences in their scalded rats [27]. Unlike humans, rats have resilient G-I tracts that function well despite such insult. However, humans have a parallel immune response to hypermetabolic stresses and tolerable nutrition changes.

For our regimen, the feeding solution used must be of low viscosity, and remain completely soluble after contact with acidic or alkaline juices (e.g., casein denatures to becomes "cheese"). Amino acids substitute nutritionally for protein in "elemental diets." This is the only type of feeding solution that we have found consistently suitable for this regimen, totally avoiding potentially obstructing whole protein and fiber for the initial 24 hours [28].

We recently reported a regimen to automate outflow monitoring from the feeding site and "refeed" the aspirate after esophagectomy. The results were identical to our previous manual experience with postoperative immediate feeding, but with a reduced nursing workload [29].

"Feeding intolerance" becomes evident only after gut recovery already has been aborted. Because "clinical judgment" alone is unreliable and "overfeeding" so detrimental, clinicians at Memorial - Sloan Kettering Cancer Center (New York, NY) [30] and the University of Ottawa [31] concluded that attempts to enterally feed immediately postoperatively were not warranted.

The New York team prospectively studied 100 pairs of matched cancer patients after resective abdominal cancer surgery. Half received closely supervised early jejunal feeding. The fed patients recovered more poorly, including one that developed bowel necrosis. They concluded that immediate enteral feeding after major resective surgery does not warrant the risks.

The Ottawa team also found that their early postoperative enteral feeding impaired recovery. They monitored preand postoperative mobility and pulmonary mechanics, to gain insight into why feeding proved detrimental. All their postoperative patients initially were bedridden. However, their fed patients were more severely affected, exhibiting poorer respiratory function, increased abdominal distention, and greater immobility.

This feeding-decompression regimen safely permits the earliest enteral feeding, despite initially impaired G-I function. More rapid return and utilization of gut function appears to reduce sepsis, mortality, discomfort, and hospital length of stay. Determining optimum nutrition in the face of the heightened metabolic demands of trauma requires further controlled study, but the "feeding intolerance" of paralytic ileus safely can be removed as a confounding factor.

\section{Conclusion}

The symptom complex of "feeding intolerance" most likely is triggered by localized distention at the enteral feeding site. It can be prevented by removing any excess liquid and all swallowed air from this location. A feedingdecompression regimen is reported that:

1. aspirates digestive juices and air from within the stomach and proximal duodenum;

2. delivers feeding solution into the slightly more distal duodenum;

3. removes excess feedings before localized distention can develop;

4. filters and returns the "degassed" aspirate via the feeding channel.

Automation can reduce the mess and nursing work-load of salvaging the aspirated digestive juices.

\section{Competing interests}

The author declares that they have no competing interests.

\section{Disclaimer}

Relating to p.5:

*For the past decade, Dr. Moss has had no financial affiliation with Moss Tubes, Inc., which manufactures Moss ${ }^{\oplus}$ medical devices and owns the trademark.

\section{References}

I. Schunn CD, Daly JM: Small bowel necrosis associated with postoperative jejunal tube feeding. J Am Coll Surg 1995, 180:410-4I6.

2. Miedema BW, Schwab J, Burgess SV, Simmons JW, Metzler MH: Jejunal manometry predicts tube feeding intolerance in the postoperative period. Dig Dis Sci 200I, 46:2250-2255.

3. Moss G: Postoperative ileus is an avoidable complication. Surg Gynecol Obstet 1979, 148:8I-82.

4. Wangensteen OH, Rea CE: The distention factor in simple intestinal obstruction; experimental study with exclusion of swallowed air by cervical esophagostomy. Surgery 1939, 5:327-339.

5. Moss G: Postoperative decompression and feeding. Surg Gynecol Obstet 1966, I 22:550-554.

6. Moss G: Nitrogen equilibrium in the early postoperative period. Surg Forum 1963, 14:67-69.

7. Kehlet H: Fast-track colorectal surgery. Lancet 2008:37I-373.

8. Basse L, Madsen JL, Billesbølle P, Bardram L, Kehlet H: Gastrointestinal transit after laparoscopic versus open colonic resection. Surg Endosc 2003, 7:1919-1922.

9. Schwenk W, Böhm B, Haase O, Junghans T, Müller JM: Laparoscopic versus conventional colorectal resection: a prospective randomised study of postoperative ileus and early postoperative feeding. Langenbecks Arch Surg 1998, 383:49-55. 
10. Hammarqvist $F$, Jacks J, Wernerman J: Effects on skeletal muscle amino acids and whole body nitrogen metabolism of total parenteral nutrition following laparoscopic cholecystectomy and given to healthy volunteers. J Clin Nutr 1998, 17:205-210.

II. Moss G: Efficient gastroduodenal decompression with simultaneous full enteral nutrition: A new gastrostomy catheter technique. J Parenter Enteral Nutr 1984, 8:203-207.

12. Moss G, Friedman RC: Abdominal decompression: Increased efficiency by esophageal aspiration utilizing a new nasogastric tube. Am J Surg 1977, 133:225-228.

13. Moss G, Bierenbaum A, Bova F, Slavin JA: Postoperative metabolic patterns following immediate total nutritional support: Hormone levels, DNA synthesis, nitrogen balance, and accelerated wound healing. J Surg Res 1976, 21:383-393.

14. Moss G: Maintenance of G-I function after bowel surgery and immediate enteral full nutrition: II. Clinical experience, with objective demonstration of intestinal absorption and motility. J Parenter Enteral Nutr 198I, 5:215-220.

15. Moss G, Nassif AC: Preserved postoperative GI function and full enteral nutrition. Surg Rounds 1986, 9:66-85.

16. Moss G: Discharge within 24 hours of elective cholecystectomy: The first 100 patients. Arch Surg 1986, 121:1159-I I6I.

17. Moss G: Raising the outcome standards for conventional "open" cholecystectomy. Am J Surg 1996, 172:383-385.

18. Moss G, Regal ME, Lichtig L: Reducing postoperative pain, narcotics, and length of hospitalization. Surgery 1986, 99:206-10.

19. Moss G: Elevation of postoperative plasma amino acid concentrations by immediate full enteral nutrition. J Am Coll Nutr 1984, 3:325-332.

20. Nassif AC, Naylor EW: Immediately elevated postoperative serum branched-chain amino acids following effective GI decompression and enteral feeding. Nutrition 1996, I 2:159-163.

21. Moss G, Greenstein A, Levy S, Bierenbaum A: Maintenance of G-I function after bowel surgery and immediate enteral full nutrition: I. Doubling of canine colorectal anastomotic bursting pressure and intestinal wound mature collagen content. J Parenter Enteral Nutr 1980, 4:535-538.

22. Schroeder D, Gillanders L, Mahr K, Graham L: Effects of immediate postoperative enteral nutrition on body composition, muscle function, and wound healing. I Parenter Enteral Nutr 1991, I 5:376-383.

23. Moss G: Immediately postoperative full nutrition and sepsis resistance: Immune globulin synthesis. J Parenter Enteral Nutr 1977, I:36A.

24. Seidmon EJ, Pizzimenti KV, Blumenstock FA, Wajsman Z, Pontes JE: Immediate postoperative feeding, positive protein balance, and fibronectin elevation following radical urologic surgery. J Am Coll Nutr 1983, 2:3।I.

25. Seidmon EJ, Pizzimenti KV, Blumenstock FA, Huben RP, Wajsman Z, Pontes JE: Immediate postoperative feeding in urological surgery. J Urol 1984, I3 I:I I I3-I I I8.

26. Härtl R, Gerber LM, Ni Q, Ghajar J: Effect of early nutrition on deaths due to severe traumatic brain injury. J Neurosurg 2008, 109:50-56.

27. Jeschke MG, Herndon DN, Ebener C, Barrow RE, Jauch K-W: Nutritional intervention high in vitamins, protein, amino acids, and omega-3 fatty acids improves protein metabolism during the hypermetabolic state after thermal injury. Arch Surg 200I, 1 36: I30I-1306

28. Moss G: Immediately postoperative enteral feeding. In Uses of Elemental Diets in Clinical Situations Volume Chapter II. Edited by: Bounous G. CRC Press, Boca Raton; 1992.

29. Moss G: Gastrointestinal monitor: automatic titration of jejunal inflow to match peristaltic outflow. I Surg Res 2007, 140:184-188.

30. Heslin MJ, Latkany L, Leung D, Brooks AD, Hochwald SN, Pisters PW, Shike M, Brennan MF: A prospective, randomized trial of early enteral feeding after resection of upper gastrointestinal malignancy. Ann Surg 1997, 226:567-577.

31. Watters JM, Kirkpatrick SM, Norris SB, Shamji FM, Wells GA: Immediate postoperative enteral feeding results in impaired respiratory mechanics and decreased mobility. Ann Surg 1997, 226:369-377.
Publish with Biomed Central and every scientist can read your work free of charge

"BioMed Central will be the most significant development for disseminating the results of biomedical research in our lifetime. "

Sir Paul Nurse, Cancer Research UK

Your research papers will be:

- available free of charge to the entire biomedical community

- peer reviewed and published immediately upon acceptance

- cited in PubMed and archived on PubMed Central

- yours - you keep the copyright

Submit your manuscript here:

http://www.biomedcentral.com/info/publishing_adv.asp
BiolMedcentral 